\title{
The Relationship between Leukocyte Counts and Venous Thromboembolism: Results from RETROVE Study
}

Noelia Vilalta ${ }^{1 *}$, Miquel Vázquez-Santiago ${ }^{1,2}$, Biel Cuevas $^{1}$, Raquel Macho ${ }^{1}$, Angel Remacha ${ }^{3}$, Marina Carrasco ${ }^{1}$, José Mateo ${ }^{1}, J_{u a n}$ Millón $^{1}$, José Manuel Soria $^{2}$ and Juan Carlos Souto 1

${ }^{1}$ Unitat d'Hemostàsia i Trombosi, Hospital de la Santa Creu i Sant Pau, Sant Antoni Maria Claret, 167, Barcelona, Spain

${ }^{2}$ Unitat de Genòmica i Malalties Complexes, Hospital de la Santa Creu i Sant Pau, Sant Antoni Maria Claret, 167, Barcelona, Spain

${ }^{3}$ Departament d'Hematologia, Hospital de la Santa Creu i Sant Pau, Sant Antoni Maria Claret, 167, Barcelona, Spain

*Corresponding author: Noelia Vilalta, Unitat d'Hemostàsia i Trombosi, Hospital de la Santa Creu i Sant Pau, Sant Quintí 89, Barcelona, Spain 08026, Tel: +34 9335537151; Fax: +34 9335537153; E-mail: NVilalta@santpau.cat

Received date: May 31, 2017; Accepted date: June 20, 2017; Published date: June 27, 2017

Copyright: (c) 2017 Vilalta N, et al. This is an open-access article distributed under the terms of the Creative Commons Attribution License, which permits unrestricted use, distribution, and reproduction in any medium, provided the original author and source are credited.

\begin{abstract}
Introduction: Different studies have shown a possible increased risk of venous thromboembolism (VTE) and arterial thrombosis in patients with an increased leukocyte count. The underlying mechanisms are not completely understood, but they could partly be explained by the role that white blood cells play in inflammation. Our objective is to investigate investigated the relationship between leukocyte counts and VTE.
\end{abstract}

Material and methods: Analyses were performed in 400 patients and 400 control subjects of the RETROVE (Riesgo de Enfermedad TROmboembólica VEnosa) Study. To evaluate the odds ratio (OR) for VTE of leukocyte counts we used an unconditional logistic regression analysis taking into account the confounders.

Results: We observed more spontaneous $(273,68.3 \%)$ than non-spontaneous (127, 31.8\%) VTE. Monocyte counts showed a strong association with thrombosis risk: For the 90th percentile in the controls $\left(>0.7 \times 10^{9} / \mathrm{L}\right)$, the OR of VTE and its $95 \%$ confidence intervals are 2.1 (1.4-3.3). A highly significant relation between high monocyte counts and spontaneous VTE was found.

Conclusion: We confirmed a strong association between high monocyte counts and past VTE. High monocyte counts (even within the clinical reference range) could constitute a risk factor for VTE.

Keywords: Venous thromboembolism; Arterial thrombosis; Leukocyte count

\section{Introduction}

Deep vein thrombosis (DVT) and pulmonary embolism (PE) are referred to as venous thromboembolism (VTE). These diseases are a leading cause of mortality.

Venous thrombi have a characteristic laminar structure. The thrombi are rich in fibrin and red blood cells and are accompanied by a large number of leukocytes. There is increasing evidence [1] that inflammatory processes and DVT are closely related. Inflammation and haemostasis are related via common activation pathways and feedback regulation. Inflammation disrupts the haemostatic equilibrium, which causes thrombosis.

A study [2] using a mouse model of flow restriction-induced DVT without endothelium damage, showed that the reduction of blood flow induced a proinflammatory endothelial condition. This condition recruits innate immune cells, particularly neutrophils and monocytes. In addition, there is evidence [3,4] highlighting the intervention of leukocytes in thrombosis. Several mechanisms have been postulated $[5,6]$ to explain the effect of high leukocyte counts on ischemic vascular events. Notably, the thrombotic effect is due to tissue factor (TF) in monocytes, neutrophils and microparticles (MPs) [5,7]. Neutrophils promote thrombus formation through different mechanisms. They adhere to injured vessels immediately, preceding platelets through an interaction between leukocyte function associated antigen and ICAM-1 [8]. This is an important step for the activation and accumulation of thrombocytes. The neutrophil extracellular traps [9] and platelet-leukocyte aggregates [10] are other mechanisms that explain the association between leukocyte and VTE. Monocytes are the major source of TF. They are important regulators of blood thrombosis via the expression of $\mathrm{TF}$ on their surface and the shedding of procoagulant MPs under various pathologic conditions [11].

The Tromsø study [11] found that high monocyte counts constitute a risk factor for VTE. In support of this hypothesis, patient monocytes, expressed higher levels of TF protein than in the controls. The MEGA study [12] (a case-control study) found that a high peripheral monocyte count (above $0.55 \times 10^{9} / \mathrm{L}$ ), even within the reference range, was associated with DVT in a dose-response manner: odds ratio (OR) 2.8 and $95 \%$ confidence interval [CI], 1.3-5.8.

Other studies $[6,13,14]$ have shown that high leukocyte counts are a predictor of VTE in patients with myeloproliferative disorders, but, in patients without such diseases, there is few data available and the mechanism is not known. 


\section{Methods}

\section{Sample}

Individuals were recruited from the RETROVE (Riesgo de Enfermedad TROmboembólica VEnosa) Project at the Hospital de la Santa Creu i Sant Pau of Barcelona between 2012 and 2016. RETROVE is a prospective case-control study which includes 400 consecutive adult patients (over 18 years old) with VTE (according to specific clinical inclusion criteria) diagnosed during the study period and 400 healthy volunteers who serve as controls. Detailed population characteristics are described in Table 1. The goals of the RETROVE Project are to identify new biomarkers for VTE and to establish mathematical algorithms to predict thrombotic risk.

\begin{tabular}{|c|c|c|c|c|c|}
\hline & \multicolumn{2}{|l|}{ Patients } & \multicolumn{2}{|l|}{ Controls } & \multirow[t]{2}{*}{ p-values ${ }^{\partial}$} \\
\hline & Male & Female & Male & Female & \\
\hline \multicolumn{6}{|c|}{ Demographics } \\
\hline Number & 196 & 204 & 194 & 206 & n.s. \\
\hline Age $^{*}$ & $\begin{array}{l}63 \quad(19- \\
95)\end{array}$ & $\begin{array}{l}72 \quad(23- \\
96)\end{array}$ & $\begin{array}{l}46 \quad(21- \\
90)\end{array}$ & $\begin{array}{l}49 \\
94)\end{array}$ & $<2.2 \times 10^{-16}$ \\
\hline $\mathrm{BMI}^{\dagger}$ & $28 \pm 4$ & $28 \pm 6$ & $26 \pm 4$ & $25 \pm 4$ & $<2.2 \times 10^{-16}$ \\
\hline \multicolumn{6}{|l|}{ Risk Factors } \\
\hline Smoking & $\begin{array}{l}37 \\
(18.9 \%)\end{array}$ & $18(8.8 \%)$ & $\begin{array}{l}40 \\
(20.6 \%)\end{array}$ & $\begin{array}{l}35 \\
(17.0 \%)\end{array}$ & n.s. \\
\hline Hypertension & $\begin{array}{l}83 \\
(42.3 \%)\end{array}$ & $\begin{array}{l}94 \\
(46.1 \%)\end{array}$ & $\begin{array}{l}35 \\
(18.0 \%)\end{array}$ & $\begin{array}{l}40 \\
(19.4 \%)\end{array}$ & $8.27 \times 10^{-15}$ \\
\hline Dyslipidaemia & $\begin{array}{l}62 \\
(31.6 \%)\end{array}$ & $\begin{array}{l}75 \\
(36.8 \%)\end{array}$ & $\begin{array}{l}36 \\
(18.6 \%)\end{array}$ & $\begin{array}{l}43 \\
(20.9 \%)\end{array}$ & $3.46 \times 10^{-6}$ \\
\hline $\begin{array}{l}\text { Diabetes } \\
\text { mellitus }\end{array}$ & $\begin{array}{l}23 \\
(11.7 \%)\end{array}$ & $17(8.3 \%)$ & $10(5.2 \%)$ & $10(4.9 \%)$ & 0.0073 \\
\hline $\begin{array}{l}\text { Chronic } \\
\text { obstructive } \\
\text { pulmonary } \\
\text { disease }\end{array}$ & $\begin{array}{l}23 \\
(11.7 \%)\end{array}$ & 11 (5.4\%) & $3(1.6 \%)$ & $5(2.4 \%)$ & $3.76 \times 10^{-5}$ \\
\hline $\begin{array}{l}\text { Kidney } \\
\text { disease }\end{array}$ & $10(5.1 \%)$ & $10(4.9 \%)$ & $2(1.0 \%)$ & $4(1.9 \%)$ & 0.0052 \\
\hline $\begin{array}{l}\text { Autoimmune } \\
\text { disease }\end{array}$ & $\begin{array}{l}20 \\
(10.2 \%)\end{array}$ & $\begin{array}{l}21 \\
(10.3 \%)\end{array}$ & $14(7.2 \%)$ & $18(8.7 \%)$ & n.s. \\
\hline
\end{tabular}

$\left(^{*}\right)$ Medians (years) and minimum and maximum between parentheses

$\left({ }^{\dagger}\right)$ Body mass index is given in kilogram per square meters.

$\left({ }^{\partial}\right)$ The statistical differences, fixed in a $p$ value $<0.05$, are reported for descriptive purposes only.

Table 1: Demographic characteristics and risk factors for patients and controls.

The diagnosis of thrombosis was based on doppler ultrasonography, tomography, magnetic resonance, arteriography, phlebography, pulmonary gammagraphy and plethysmography. Any type of thrombosis was included except those related to cancer. VTE was classified as either unprovoked or spontaneous or provoked or nonspontaneous (one or more provoking factors within 3 months previous to an event) $[15,16]$. In this last group, provoking factors were: surgery, immobilization, pregnancy, oral contraceptive, prothrombotic nonneoplastic diseases and others. For the control group, 400 healthy individuals who were friends, partners or volunteers (non-related with cases and neither among them) were included and they were distributed according to age and sex distribution of the a Spanish population (2001 census).

Our study was performed in accordance with the ethical guidelines of the Declaration of Helsinki. Written informed consent at the moment of the inclusion (in the case of patients, the first visit during the diagnosis of VTE) was obtained from all participants and all the procedures were approved by the Institutional Review Board at the Hospital de la Santa Creu i Sant Pau.

\section{Blood collection and measure of parameters}

Blood samples for study were collected from antecubital vein between 9:00 a.m. and 12:00 p.m., under basal conditions and after 12hour overnight fasting.

Leukocyte counts (eosinophils, monocytes, lymphocytes, neutrophils and basophils) were measured in whole blood drawn into $5 \mathrm{ml}$ vacutainer tubes (Becton Dickinson and Company, New Jersey, USA) containing EDTA ( $40 \mu \mathrm{L}$ of K3-EDTA, $0.37 \mathrm{~mol} / \mathrm{L}$ per tube). The samples were analysed within 2 hours in an automated haematological analyser Sysmex XE-2100 (Roche Diagnostics, Basel, Switzerland). To establish the real basal status of the patients, samples were taken 6 months after thrombosis. To avoid possible interferences in coagulation parameters determination, none of the participants was using oral anticoagulants or heparin at the time of blood collection. In cases when this treatment could not be stopped, patients were treated with heparin and they omit the dose of the day before the blood extraction.

\section{Statistical analysis}

The chi-square $\left(\chi^{2}\right)$ test was used to compare between pairs of categorical variables such as: gender, smoking, hypertension, dyslipidaemia, diabetes mellitus, chronic obstructive pulmonary disease, kidney disease and autoimmune disease. The non-parametric Mann-Whitney test was used to test differences between mean values of the leukocyte counts. Because of the age and gender difference between the patients and the controls, we evaluated in our RETROVE controls the effect of these variables on leukocyte counts using a linear regression model, as reported previously [17-21]. The ages of the experimental group of patients were from 19 to 96 . In contrast, the ages of the controls were from 21 to 94 years.

To study if low or high levels of leukocyte counts correlate with VTE, we established two cut-off points one at 10th percentile and another at 90th percentile. Potential confounders (age and gender) were adjusted with an unconditional logistic regression analysis.

We focused our attention on monocytes counts because they exhibited the highest thrombotic risk. Also, we calculated the OR and $95 \%$ CI according to the spontaneous or non-spontaneous origin of VTE and if the patients had previous thrombotic events. To determine if there is an association between monocyte counts and risk of VTE, we used an unconditional logistic regression model. The $\mathrm{p}$ values below 0.05 were considered statistically significant. 
Citation: Vilalta N, Vázquez-Santiago M, Cuevas B, Macho R, Remacha A, et al. (2017) The Relationship between Leukocyte Counts and Venous Thromboembolism: Results from RETROVE Study. Biol Med (Aligarh) 9: 400. doi:10.4172/0974-8369.1000400

Page 3 of 5

\section{Results}

\section{Demographic variables and risk factors}

The demographic variables and risk factors of the patients and controls are summarized in Table 1. There are significant differences between patients and controls for age, body mass index (BMI), hypertension, dyslipidaemia, diabetes mellitus, chronic obstructive pulmonary disease and kidney disease. The results have been adjusted according these parameters. No significant differences were found for gender, smoking and autoimmune diseases.

We observed significantly more spontaneous $(273,68.3 \%)$ than non-spontaneous VTE $(127,31.8 \%)$. In both groups, the most prevalent VTE types are DVT alone or associated with PE or PE alone. Of the 400 adult patients, 315 of them at the time of the inclusion had a first thrombosis, while 71 patients had a history of previous thrombosis, 11 had two previous thrombosis and 3 had three previous thrombosis. The characteristics of the inclusion thrombotic event are summarized in Table 2.

\section{Leukocyte counts}

Leukocyte counts in patients and controls are summarized in Table 3. We found statistically significant differences between means of patients and controls for monocytes, neutrophils and basophils counts. Notably, the monocyte counts in the patients were very highly statistically significant ( $\mathrm{p}$ value $=1.22 \times 10^{-5}$ ). In contrast, the basophil count showed slightly low mean values in patients $(0.030 \pm 0.017)$ rather than controls $(0.033 \pm 0.019)$. No differences in leukocyte counts between males and females were seen.

\begin{tabular}{|c|c|c|c|c|c|c|}
\hline & \multicolumn{3}{|c|}{ Spontaneous } & \multicolumn{3}{|c|}{ Non-spontaneous } \\
\hline & Males* & Female* $^{*}$ & Total $^{\dagger}$ & Males* & Female* & Total $^{\dagger}$ \\
\hline Isolated deep vein thrombosis & $82(56.2 \%)$ & $63(49.6 \%)$ & $145(53.1 \%)$ & $27(54.0 \%)$ & 38 (49.4\%) & $65(51.2 \%)$ \\
\hline $\begin{array}{l}\text { Deep vein thrombosis plus } \\
\text { pulmonary embolism }\end{array}$ & $30(20.6 \%)$ & $19(15.0 \%)$ & $49(18.0 \%)$ & $10(20.0 \%)$ & $11(14.3 \%)$ & $21(16.5 \%)$ \\
\hline Isolated pulmonary embolism & $31(21.2 \%)$ & $42(33.1 \%)$ & $73(26.7 \%)$ & $12(24.0 \%)$ & $26(33.8 \%)$ & $38(29.9 \%)$ \\
\hline Visceral thrombosis & $2(1.4 \%)$ & - & $2(0.7 \%)$ & $1(2.0 \%)$ & - & $1(0.8 \%)$ \\
\hline $\begin{array}{l}\text { Cerebral venous sinus } \\
\text { thrombosis }\end{array}$ & $1(0.7 \%)$ & $3(2.4 \%)$ & $4(1.5 \%)$ & - & $2(2.6 \%)$ & $2(1.6 \%)$ \\
\hline Total $^{\#}$ & $146(36.5 \%)$ & $127(31.8 \%)$ & $273(68.3 \%)$ & $50(12.5 \%)$ & $77(19.3 \%)$ & $127(31.8 \%)$ \\
\hline
\end{tabular}

$\left(^{*}\right)$ Percentages were obtained from number of thrombosis types divided by total number of males or females.

$\left(^{\dagger}\right)$ Percentages were obtained from number of thrombosis types divided by total number of spontaneous or non-spontaneous events.

(\#) Percentages were obtained from number of male, female or total divided by total number of patients or controls.

Table 2: Characteristics of thrombotic events.

\begin{tabular}{|c|c|c|c|c|c|}
\hline & \multicolumn{2}{|c|}{ Patients } & \multicolumn{2}{|c|}{ Controls } & \multirow{3}{*}{$\begin{array}{l}\text { p-values }{ }^{\partial} \\
\text { n.s. }\end{array}$} \\
\hline & $\mathrm{n}^{*}$ & Mean $\pm \mathrm{SD}^{\dagger}$ & $\mathrm{n}^{*}$ & Mean $\pm \mathrm{SD}^{\dagger}$ & \\
\hline Eosinophils & 398 & $0.18 \pm 0.14$ & 394 & $0.19 \pm 0.15$ & \\
\hline Monocytes & 400 & $0.57 \pm 0.20$ & 396 & $0.51 \pm 0.18$ & $1.22 \times 10^{-5}$ \\
\hline $\begin{array}{l}\text { Lymphocyte } \\
\text { s }\end{array}$ & 396 & $1.9 \pm 0.6$ & 400 & $2.0 \pm 0.5$ & n.s. \\
\hline Neutrophils & 400 & $4.1 \pm 1.5$ & 396 & $3.8 \pm 1.5$ & $6.8 \times 10^{-3}$ \\
\hline Basophils & 396 & $0.030 \pm 0.017$ & 392 & $0.033 \pm 0.019$ & 0.047 \\
\hline \multicolumn{6}{|c|}{ All leucocyte counts are given in $10 \% / \mathrm{L}$. } \\
\hline \multicolumn{6}{|c|}{$\left({ }^{*}\right)$ Number of individuals. } \\
\hline \multicolumn{6}{|c|}{$\left(^{\dagger}\right)$ Means of leukocyte counts and standard deviations (SD). } \\
\hline \multicolumn{6}{|c|}{$(\partial)$ The statistical significances are fixed in $p$ value $<0.05$. } \\
\hline
\end{tabular}

Table 3: The leukocyte counts in patients in the RETROVE project.

\section{VTE risk and monocyte counts}

As shown in Table 4, the only significant counts where with the monocytes over 90th. Only monocyte counts, higher than $0.7 \times 10^{9} / \mathrm{L}$, showed a statistically significant $\mathrm{p}$ value $(0.000112)$.

Since we found a highly significant difference of monocyte counts between patients and controls, we analysed these differences between spontaneous and non-spontaneous thrombosis and with single and multiple thrombotic events. Only spontaneous thrombosis and single events OR 2.3 (1.4-3.7) and 2 (1.3-3.2) respectively, showed a statistically significant $\mathrm{p}$ value as shown in Table 5. Although nonspontaneous cases did not show significant $\mathrm{p}$ value, but, the OR (1.6) and the CI (0.9-2.8) showed a similar tendency as spontaneous events.

\begin{tabular}{|c|c|c|c|c|}
\hline & Patients* & Controls* & OR $(95 \% \mathrm{Cl})^{\dagger}$ & p-values \\
\hline \multicolumn{5}{|l|}{ Monocytes } \\
\hline$[0.21-0.34)$ & 13 & 18 & $0,8(0.38-1.65)$ & n.s \\
\hline$[0.34-0.7)$ & 302 & 335 & 1 & - \\
\hline$[0.70-1.60)$ & 85 & 43 & $2.19(1.48-3.29)$ & 0.000112 \\
\hline
\end{tabular}


Page 4 of 5

\begin{tabular}{|l|l|l|l|l|}
\hline \multicolumn{5}{|l|}{ Neutrophils } \\
\hline$[1.20-2.3)$ & 27 & 44 & $0.59(0.36-0.98)$ & n.s \\
\hline$[2.3-5.53)$ & 319 & 309 & 1 & - \\
\hline$[5.53-13.00)$ & 54 & 40 & $1.22(0.79-1.88)$ & n.s. \\
\hline Basophils \\
\hline$[0-0.01)$ & 63 & 57 & $1.09(0.74-1.64)$ & n.s \\
\hline$[0.001-0.059)$ & 298 & 295 & 1 & - \\
\hline$[0.059-0.12)$ & 35 & 40 & $0.87(0.53-1.4)$ & n.s. \\
\hline Alleuk0ct & & &
\end{tabular}

All leukocyte counts are given in $10^{9} / \mathrm{L}$

$\left({ }^{*}\right)$ Number of individuals.

$\left.{ }^{\dagger}\right)$ Odd ratios are adjusted by age, gender, BMI, hypertension, dyslipidaemia, diabetes mellitus, chronic obstructive pulmonary disease and kidney disease. The confidence intervals $(\mathrm{Cl})$ are given between the parentheses.

$(\#)$ The statistical differences are fixed in $p$ value $<0.05$.

Table 4: Odd ratios of venous thromboembolism events, taking in account the 10th and the 90th percentile of the controls, for monocytes, neutrophils and basophils.

\begin{tabular}{|c|c|c|c|c|c|}
\hline & $\begin{array}{l}\text { Monocyte } \\
\text { groups }\end{array}$ & $\begin{array}{l}\text { Patients } \\
*\end{array}$ & $\begin{array}{l}\text { Control } \\
\mathbf{s}^{*}\end{array}$ & OR $(95 \% \text { Cl) })^{\dagger}$ & $p$-values \\
\hline \multirow{3}{*}{$\begin{array}{l}\text { Spontaneo } \\
\text { us events }\end{array}$} & $(0.21-0.34)$ & 11 & 18 & $\begin{array}{l}1.2 \\
(0.47-2.86)\end{array}$ & n.s \\
\hline & $(0.34-0.7)$ & 199 & 335 & 1 & - \\
\hline & $(0.70-1.60)$ & 63 & 43 & $2.3(1.4-3.7)$ & $0.1 \times 10^{-3}$ \\
\hline \multirow{3}{*}{$\begin{array}{l}\text { Non- } \\
\text { spontaneo } \\
\text { us events }\end{array}$} & $(0.21-0.34)$ & 2 & 18 & $0.4(0.05-1.3)$ & n.s \\
\hline & $(0.34-0.7)$ & 103 & 335 & 1 & - \\
\hline & $(0.70-1.60)$ & 22 & 43 & $1.6(0.9-2.8)$ & n.s. \\
\hline \multirow{3}{*}{ Single } & $(0.21-0.34)$ & 10 & 18 & $0.8(0.3-1.8)$ & n.s \\
\hline & $(0.34-0.7)$ & 233 & 335 & 1 & - \\
\hline & $(0.70-1.60)$ & 72 & 43 & $2(1.3-3.2)$ & $0.2 \times 10^{-3}$ \\
\hline \multirow{3}{*}{ Multiple } & $(0.21-0.34)$ & 3 & 18 & $\begin{array}{l}0.99 \\
(0.2-3.49)\end{array}$ & n.s \\
\hline & $(0.34-0.7)$ & 69 & 335 & 1 & - \\
\hline & $(0.70-1.60)$ & 13 & 43 & $\begin{array}{l}1.5 \\
(0.71-3.14)\end{array}$ & n.s \\
\hline
\end{tabular}

$\left(^{*}\right)$ Number of individuals.

$\left.{ }^{\dagger}\right)$ Odd ratios were adjusted by age, gender, BMI, hypertension, dyslipidaemia, diabetes mellitus, chronic obstructive pulmonary disease and kidney disease. The confidence intervals $(\mathrm{Cl})$ are given within the parentheses.

$(\#)$ The statistical differences are fixed in $p$ value $<0.05$.

Table 5: Odd ratios of spontaneous, non-spontaneous venous thromboembolism and single - multiple events taking into account the 90th percentile for monocyte counts of the controls.

\section{Discussion and Conclusion}

We investigated the effect of leukocyte, and particularly monocyte counts, as VTE risk factors. Patients and controls showed statistical significant differences in their risk factors. These differences may be due to the fact that in general the patients were older than the controls and also to the particular design of the RETROVE Study as mentioned previously.

Some studies $[15,22]$ reported an equal prevalence of spontaneous and non-spontaneous VTE. However, we observed a high prevalence of spontaneous VTE (68.3\%) versus non-spontaneous (31.8\%). This difference may be due to the use of pharmacological VTE prophylaxis in patients with thrombotic risk factors. Also it could be that in patients who had surgical procedures or long immobilization periods. The localization of VTE in our patients was similar to those previously reported [15].

Recent studies $[2,23,24]$ indicate that the recruitment and activation of neutrophils and monocytes secondary to stasis (and not endothelial injury) are early events in VTE. Leukocytes play a role in coagulation, but it is not clear if they play a role in the risk of VTE [12]. In our sample, patients had increased counts of neutrophils and monocytes. Notably, we found statistically significance for spontaneous events with monocyte counts over the ninetieth percentile (over $0.7 \times 10^{-9} / \mathrm{L}$ ) with a $\mathrm{p}$ value of $5.52 \times 10^{-4}$. High monocyte counts were found in both spontaneous and non-spontaneous VTE. These findings were not unexpected because induction of TF expression on monocytes has been implicated in thrombotic disorders. Circulating monocytes express TF in response to inflammatory stimuli and some studies have demonstrated that the source of TF in VT essentially came from leukocytes, primarily monocytes and from monocyte- derived microparticles (MPs) [2]. Also, homocysteine and an increase of TF has been reported $[25,26]$ for monocytes in patients with cirrhosis or sepsis and even in patients after surgery. Furthermore, monocytes are involved in the modulation of venous thrombus [27-29].

A methodological issue in our study needs to be addressed. Specifically, the leukocyte parameters were measured at least six months after the thrombotic event. We do not know if our results would be different if we studied patients during the acute phase.

However, we are confident that our finding that high monocyte counts, even within the reference range (above $0.7 \times 10^{9} / \mathrm{L}$ ) are associated with VTE. These results confirm and extend what has been reported previously in other studies $[11,12]$. However in our study we found a highly statistically significance association of monocytes and previous VTE (OR 2.47 and p value $2.49 \times 10^{-4}$ ). In this way, we did not find differences if the patient had history of one or more previous thrombosis. It is obvious that our results do not exclude the possibility that there is a relationship between other types of leukocytes and thrombosis. We don't know if there is a causal relationship between high monocyte levels and the disease because our sample has been taken after the thrombotic episode, but, our findings, are in line of Troms $\varnothing$ and MEGA studies [11,12] and they support that high monocyte counts are in association with past VTE. We believe that our results provide a firm foundation for additional studies and they suggest that a high monocyte count are related with VTE risk and could be a useful parameter in future prediction models. 
Citation: Vilalta N, Vázquez-Santiago M, Cuevas B, Macho R, Remacha A, et al. (2017) The Relationship between Leukocyte Counts and Venous Thromboembolism: Results from RETROVE Study. Biol Med (Aligarh) 9: 400. doi:10.4172/0974-8369.1000400

Page 5 of 5

\section{Acknowledgements}

The authors thank the individuals who participated in the RETROVE study. We also would like to thank Professor Bill Stone for editing the manuscript.

Biel Cuevas and Raquel Macho performed the research. Juan Carlos Souto, Jose Mateo, Marina Carrasco and Juan Millon designed the research protocols. Angel Remacha and José Manuel Soria contributed essential reagents or tools. Noelia Vilalta and Miquel Vazquez-Santiago analysed the data. Noelia Vilalta and Miquel Vazquez-Santiago wrote the paper. All the authors approved the final version of this manuscript.

This study was supported in part by the Spanish grant: Red Investigación Cardiovascular RD12/0042/0032, FIS PI 12/0612 and FIS PI $15 / 0269$.

\section{References}

1. Kageyama K, Nakajima Y, Shibasaki M, Hashimoto S, Mizobe T (2007) Increased platelet, leukocyte, and endothelial cell activity are associated with increased coagulability in patients after total knee arthroplasty. J Thromb Haemost 5: 738-745.

2. von Brühl ML, Stark K, Steinhart A, Chandraratne S, Konrad I, et al (2012) Monocytes, neutrophils, and platelets cooperate to initiate and propagate venous thrombosis in mice in vivo. J Exp Med 209: 819-835.

3. Van Montfoort ML, Stephan F, Lauw MN, Hutten BA, Van Mierlo GJ, et al. (2013) Circulating nucleosomes and neutrophil activation as risk factors for deep vein thrombosis, Arterioscler Thromb Vasc Biol 33: 147-151.

4. M Kushnir, HW Cohen, HH Billett (2016) Persistent neutrophilia is a marker for an increased risk of venous thrombosis. J Thromb Thrombolysis 42: 545-51

5. Coller BS (2005) Leukocytosis and ischemic vascular disease morbidity and mortality: is it time to intervene? Arterioscler Thromb Vasc Biol 25: 658-670.

6. Barbui T, Carobbio A, Rambaldi A, Finazzi G (2009) Perspectives on thrombosis in essential thrombocythemia and polycythemia vera: Is leukocytosis a causative factor? Blood 114: 759-763.

7. Darbousset R, Thomas GM, Mezouar S, Frere C, Bonier R, et al. (2012) Tissue factor-positive neutrophils bind to injured endothelial wall and initiate thrombus formation. Blood 120: 2133-2143.

8. Ruhnau J, Schulze J, Dressel A, Vogelgesang A (2017) Thrombosis, neuroinflammation, and poststroke infection: The multifaceted role of neutrophils in stroke. J Immunol Res 2017: 5140679.

9. Fuchs TA, Brill A, Wagner DD (2012) Neutrophil extracellular trap (NET) impact on deep vein thrombosis, Arterioscler. Thromb Vasc Biol 32: $1777-1783$.

10. Freedman JE, Loscalzo J (2002) Platelet-monocyte aggregates: bridging thrombosis and inflammation. Circulation 105: 2130-2132.

11. Basavaraj MG, Braekkan SK, Brodin E, Osterud B, Hansen JB (2011) Monocyte count and procoagulant functions are associated with risk of venous thromboembolism: the Tromsøstudy. J Thromb Haemost 9: 1673-1676.
12. Rezende SM, Lijfering WM, Rosendaal FR, Cannegieter SC (2014) Hematologic variables and venous thrombosis: Red cell distribution width and blood monocyte count are associated with an increased risk. Haematologica 99: 194-200.

13. Gangat N, Strand J, Li CY, Wu W, Pardanani A, et al. (2007) Leucocytosis in polycythaemia vera predicts both inferior survival and leukaemic transformation. Br J Haematol 138: 354-358.

14. Palandri F, Polverelli N, Catani L, Ottaviani E, Baccarani M, et al. (2011) Impact of leukocytosis on thrombotic risk and survival in 532 patients with essential thrombocythemia: a retrospective study. Ann Hematol 90: 933-938.

15. Martinez C, Cohen AT, Bamber L, Rietbrock S (2014) Epidemiology of first and recurrent venous thromboembolism: a population-based cohort study in patients without active cancer. Thromb Haemost 112: 255-263.

16. Kearon C, Ageno W, Cannegieter SC, Cosmi B, Geersing GJ, et al. (2016) Categorization of patients as having provoked or unprovoked venous thromboembolism: guidance from the SSC of ISTH. J Thromb Haemost 14: 1480-1483.

17. Vázquez-Santiago M, Ziyatdinov A, Pujol-Moix N, Brunel H, Morera A, et al. (2016) Age and gender effects on 15 platelet phenotypes in a Spanish population. Comput Biol Med 69: 226-233.

18. Nilsson-Ehle H, Jagenburg R, Landahl S, Svanborg A, Westin J (1988) Haematological abnormalities and reference intervals in the elderly. A cross-sectional comparative study of three urban Swedish population samples aged 70, 75 and 81 years. Acta Med Scand 224: 595-604.

19. Polednak AP (1978) Age changes in differential leukocyte count among female adults. Hum Biol 50: 301-311.

20. Allan RN, Alexander MK (1968) A sex difference in the leucocyte count. J Clin Pathol 21: 691-694.

21. Lenth RV (2016) Least-squares means: the R Package lsmeans. J Stat Softw 69: 1-33.

22. RH White (2003) The epidemiology of venous thromboembolism. Circulation 107: I4-18.

23. Brill A, Fuchs TA, Savchenko AS, Thomas GM, Martinod K (2012) Neutrophil extracellular traps promote deep vein thrombosis in mice. J Thromb Haemost 10: 136-144.

24. Massberg SS (2012) Platelets in atherosclerosis and thrombosis. Handb Exp Pharmacol 210: 111-33.

25. Houston KDS (2000) Induction of monocyte tissue factor expression by homocysteine: a possible mechanism for thrombosis. Blood 96: 966-972.

26. Go SI, Kim RB, Song HN, Kang MH, Lee US, et al. (2015) Prognostic significance of the absolute monocyte counts in lung cancer patients with venous thromboembolism. Tumor Biol 36: 7631-7639.

27. Henke PK, Varga A, De S, Deatrick CB, Eliason J, et al. (2004) Deep vein thrombosis resolution is modulated by monocyte CXCR2-mediated activity in a mouse model. Arterioscler Thromb Vasc Biol 24: 1130-1137.

28. Henke PK, Pearce CG, Moaveni DM, Moore AJ, Lynch EM, et al. (2006) Targeted deletion of CCR2 impairs deep vein thombosis resolution in a mouse model. J Immunol 177: 3388-3397.

29. Ali T, Humphries J, Burnand K, Sawyer B, Bursill C, et al. (2006) Monocyte recruitment in venous thrombus resolution. J Vasc Surg 43: 601-608. 